\title{
Survival benefit of adjuvant radiotherapy in stage III and IV bladder cancer: results of 170 patients
}

This article was published in the following Dove Press journal:

Cancer Management and Research

27 November 2014

Number of times this article has been viewed

\author{
Yasser Bayoumi' \\ Tarek Heikal \\ Hossam Darweish ${ }^{2}$ \\ 'Radiation Oncology, National Cancer \\ Institute, Cairo University, Giza, Egypt; \\ ${ }^{2}$ Medical Oncology, Damietta Cancer \\ Institute, Ministry of Health, \\ Damietta, Egypt
}

Background: Radical cystectomy (RC) with or without neoadjuvant chemotherapy is the standard treatment for muscle-invasive bladder cancers. However, the locoregional recurrence rate is still significantly higher for locally advanced cases post-RC. The underuse of postoperative radiotherapy (PORT) in such cases after RC is related mainly to a lack of proven survival benefit. Here we are reporting our long-term Egyptian experience with bladder cancer patients treated with up-front RC with or without conformal PORT.

Patients and methods: This retrospective study included 170 locally advanced bladder cancer (T3-T4, N0/N1, M0) patients who had RC performed with or without PORT at Damietta Cancer Institute during the period of 1998-2006. The treatment outcomes and toxicity profile of PORT were evaluated and compared with those of a non-PORT group of patients.

Results: Ninety-two patients received PORT; 78 did not. At median follow-up of 47 months (range, 17-77 months), 33\% locoregional recurrences were seen in the PORT group versus $55 \%$ in the non-PORT group $(P<0.001)$. The overall distant metastasis rate in the whole group was $39 \%$, with no difference between the two groups. The 5 -year disease-free survival for the whole group of patients was $53 \% \pm 11 \%$, which was significantly affected by additional PORT, and $65 \% \pm 13 \%$ compared with $40 \% \pm 9 \%$ for the non-PORT group $(P=0.04)$. The pathological subtypes did not affect 5 -year disease-free survival significantly $(P=0.9)$. The 5 -year overall survival was $44 \% \pm 10 \%$. Using multivariate analysis, PORT, stage, and extravesical extension (positive surgical margins) were found to be important prognostic factors for locoregional control. Stage and lymph node status were important prognosticators for distant metastasis control.

Conclusion: PORT was found to be a safe and effective tool in decreasing local recurrence rates and improving disease-free survival.

Keywords: bladder cancer, postoperative radiotherapy, locoregional recurrence, overall survival

\section{Introduction}

Radical cystectomy (RC) with or without neoadjuvant chemotherapy still remains the gold standard treatment for muscle-invasive bladder cancer. Most of the studies have reported the locoregional recurrence rate (LRR), ranging from 23\% to 50\% after RC alone in locally advanced bladder cancer patients. ${ }^{1-5}$ Bladder-confined disease and extravesical extension should be distinguished to evaluate the role of postoperative radiation therapy (PORT) properly. However, retrospective data regarding PORT are insufficient, and only one prospective study that tested PORT showed improvement in disease-free survival (DFS) without any improvement in overall survival (OS). ${ }^{6-8}$ The radiation-induced late complications are the main limiting factor for the use of PORT after RC worldwide; however, the risk for radiation-induced complications can
Correspondence: Yasser Bayoumi Radiation Oncology, National Cancer Institute, Cairo University, Giza, Egypt Tel +966502785290

Email yasserbayoumi777@yahoo.com 
be minimized by novel radiotherapy techniques (conformal radiotherapy or intensity-modulated radiotherapy). ${ }^{4}$

The present study evaluates the benefit of conformal radiotherapy-based PORT in patients with nonmetastatic bladder cancer extending beyond the wall of the bladder (T3-T4) after RC, as well as its toxicity profile and its effect on DFS and OS.

\section{Patients and methods}

Bladder cancer patients treated at the Damietta Cancer Institute from 1998 to 2005 were retrospectively reviewed. During that period, 750 bladder cancer patients were treated at the institute; among those, $530(71 \%)$ patients were treated with radical intent. After meeting the eligibility criteria, 235 medical records for patients with nonmetastatic stage III and IV cancer were reviewed. Sixty-five patients were excluded because of incomplete data. The American Joint Committee of Cancer clinical staging system 2010 was used for staging patients. ${ }^{9}$ Only the patients with nonmetastatic (T3-T4, N0/1, M0) cancer who underwent RC were included in this study.

\section{Treatment techniques}

The RC procedure included the removal of the bladder, seminal vesicles, prostate, perivesical fat, and peritoneal coverage, in addition to bilateral pelvic lymphadenectomy in men. In women, it included the removal of bladder, perivesical fat and peritoneal covering, urethra, uterus, ovary, and anterior wall of the vagina.

The PORT was delivered by using linear accelerator ELEKTA dual-photon energy 6 and 10 MV. Computed tomography (CT) simulation with axial CT images was used for planning with dose calculation, using ROCS or MULTIDATA planning systems. The radiotherapy fields extended from the L5-S1 to the inferior margins of the obturator foramina if there were no prostate invasion, below the ischial tuberosity in cases of prostate invasion, and laterally to $1-2 \mathrm{~cm}$ beyond the margin of the bony pelvis at its widest part. Anteriorly, the field extends $1 \mathrm{~cm}$ beyond the symphysis pubis and posteriorly to the level of the third sacral vertebra. The clinical target volume included internal, external iliac nodal areas, and an operative bed guided by the preoperative CT data for initial tumor localization. Metal clips inserted intraoperatively were considered an excellent guide in the process of clinical target volume delineation. All patients were scheduled to receive a dose of 50 Gy in 25 fractions in a period of 5 weeks with a boost of 10 Gy to the positive margin.

\section{Follow-up}

The follow-up intervals remained every 3 months during the first and second years, then every 6 months for the following 3 years, and then annually. The follow-up procedures include CT chest, abdomen, and pelvis (annually) in addition to the routine laboratory examination and cystoscopy (every 6 months). Additional examinations were obtained when clinically needed.

\section{Statistical analysis}

Information about the clinicopathological characteristics was obtained from the clinical records. Patients with no updated information in the database were contacted through telephone calls. When updated information was not realized, those patients ( $3 \%$ of the series) were considered lost for follow-up. Data were analyzed according to the following primary and secondary end points: OS (time from the date of surgery to occurrence of death) and DFS (time from the date of surgery to occurrence of LRR or distant metastasis $[\mathrm{DM}]$ ). A statistical package software system (SPSS) was used for evaluation of the data. Descriptive statistics included values and percentages for quantitative data. Survival curves were obtained with the Kaplan-Meier method. The log-rank test was used to compare survival between groups, and a $P$-value $<0.05$ was considered statistically significant. Univariate and multivariate analyses of the prognostic features including pathological type, stage, and PORT were performed.

\section{Results}

Patient-related characteristics (age, sex, stage, lymph node involvement, surgical margin status, grade, pathological type, and PORT) are shown in Table 1. All patients underwent RC with continent/incontinent diversions, including the ureterocolic diversion $(\mathrm{n}=76)$, ureterocutaneous diversion $(n=54)$, ilial conduit $(n=34)$, and neo-bladder $(n=6)$. Ninety-two (54\%) of the 170 patients were offered radiotherapy; the remaining patients performed only RC. Ninety-nine patients were men, and 71 were women. The age of the patients varied between 32 and 73 years (mean, $58 \pm 11$ years). According to the American Joint Committee of Cancer clinical staging system, predominant preoperative stage was T2, followed by T3. One hundred four patients presented with transitional cell carcinoma, 53 patients with squamous cell carcinoma, and 13 patients with adenocarcinoma.

Eighty-five (92\%) of 92 patients completed the planned PORT. The dose ranged from 42 to $60 \mathrm{~Gy}$, with 
Table I Patients' characteristics

\begin{tabular}{|c|c|c|c|c|}
\hline Prognostic factor & All patients & $\begin{array}{l}\text { Postoperative } \\
\text { radiotherapy group }\end{array}$ & $\begin{array}{l}\text { Non-postoperative } \\
\text { radiotherapy group }\end{array}$ & $\begin{array}{l}\text { Difference } \\
P \text {-value }\end{array}$ \\
\hline Number of patients & 170 & 92 & 78 & 0.92 \\
\hline Age & $\begin{array}{l}58 \pm I I \text { (range, } \\
32-73 \text { ) }\end{array}$ & $56 \pm 7$ & $60 \pm 13$ & 0.84 \\
\hline RT dose & & $\begin{array}{l}49 \pm 6 \text { (range, 42-60); } \\
\geq 55 \mathrm{~Gy}, 28 \text { patients; } \\
\leq 55 \mathrm{~Gy}, 64 \text { patients }\end{array}$ & & \\
\hline Sex & & & & 0.02 \\
\hline Male & 99 & 70 & 29 & \\
\hline Female & 71 & 22 & 49 & \\
\hline ASA physical status & & & & 0.80 \\
\hline $\mathrm{I}-2$ & 145 & 79 & 66 & \\
\hline $3-4$ & 25 & 13 & 12 & \\
\hline 5 & - & - & - & \\
\hline \multicolumn{5}{|l|}{ Pathology type } \\
\hline Tcca & 104 & 60 & 44 & \\
\hline Sq c ca & 53 & 32 & 21 & 0.75 \\
\hline Adenocarcinoma & 13 & 0 & 13 & 0.01 \\
\hline Preoperative T stage & & & & 0.02 \\
\hline $\mathrm{T} 2$ & 77 & 39 & 38 & \\
\hline $\mathrm{T} 3$ & 72 & 37 & 35 & \\
\hline $\mathrm{T} 4$ & 21 & 16 & 5 & \\
\hline Postoperative T stage & & & & 0.82 \\
\hline T3a & 73 & 42 & 31 & \\
\hline $\mathrm{T} 3 \mathrm{~b}$ & 41 & 20 & 21 & \\
\hline $\mathrm{T} 4 \mathrm{a}$ & 37 & 19 & 18 & \\
\hline $\mathrm{T} 4 \mathrm{~b}$ & 19 & II & 8 & \\
\hline Lymph node status & & & & $<0.000$ I \\
\hline Lymph node positive & 58 & 40 & & \\
\hline Lymph node negative & 112 & 52 & & \\
\hline Surgical margin status & & & & $<0.000$ I \\
\hline Positive & 30 & 30 & 0 & \\
\hline Negative & 140 & 62 & 78 & \\
\hline Stage & & & & 0.91 \\
\hline 3 & 102 & 61 & $4 I$ & \\
\hline 4 & 68 & 31 & 37 & \\
\hline Grade & & & & 0.01 \\
\hline Low & 106 & 52 & 54 & \\
\hline High & 64 & 40 & 24 & \\
\hline
\end{tabular}

Abbreviations: Tcca, transitional cell carcinoma; Sq c ca, squamous cell carcinoma; S, significant difference; NS, nonsignificant difference; ASA, American Society of Anaesthetists.

a mean dose of $49 \pm 6$ Gy. The most common reason for not completing protocol was social issues. Among those seven patients, five were reported to be dead from cancerrelated causes.

\section{Survival analysis}

The median follow-up was 47 months (range, 17-77 months). At time of analysis, 81 (48\%) patients were alive (58\% in PORT versus $35 \%$ in non-PORT) and 89 (52\%) died. A total of $73(43 \%)$ patients developed LRR, of whom $30(33 \%)$ were in the PORT group and $43(55 \%)$ were in the nonPORT group. The overall DMR of the whole cohort was
$39 \%$, with nearly no difference between the PORT and nonPORT groups, as illustrated in Table 2. A total of 84 patients developed LRR, DM, or both.

The 5-year DFS for the whole group of patients was $53 \% \pm 11 \%$ (Table 3 ). The 5 -year DFS for the PORT group was $65 \% \pm 13 \%$ compared with $40 \% \pm 9 \%$ for the non-PORT group $(P=0.04)$, as shown in Figure 1 . The other studied factors, including stage and pathological type, showed 5 -year DFS of $60 \% \pm 15 \%$ in stage III patients compared with $20 \% \pm 6 \%$ for stage IV patients, with $P=0.02$. There were no significant difference rates of DFS according to histopathological types (transitional cell carcinoma versus squamous 
Table 2 Treatment outcome

\begin{tabular}{llll}
\hline Outcome & $\begin{array}{l}\text { All patients } \\
(\mathbf{n = 1 7 0 )}\end{array}$ & $\begin{array}{l}\text { Postoperative radiotherapy } \\
\text { group (n=92 patients; 54\%) }\end{array}$ & $\begin{array}{l}\text { Non-postoperative radiotherapy } \\
\text { group (n=78 patients; 46\%) }\end{array}$ \\
\hline $\begin{array}{l}\text { Locoregional control } \\
\text { Yes }\end{array}$ & 97 & $62(67 \%)$ & $35(45 \%)$ \\
$\quad$ No & 73 & $30(33 \%)$ & $43(55 \%)$ \\
$\begin{array}{l}\text { Distant metastasis } \\
\text { No }\end{array}$ & 104 & $56(61 \%)$ & $48(62 \%)$ \\
$\quad \begin{array}{l}\text { Yes } \\
\text { Survival status }\end{array}$ & 66 & $36(39 \%)$ & $30(38 \%)$ \\
$\quad$ Alive & 81 & $54(58 \%)$ & $27(35 \%)$ \\
$\quad$ Dead & 89 & $38(42 \%)$ & $51(65 \%)$ \\
\hline
\end{tabular}

cell carcinoma with the exclusion of adenocarcinoma), with a $P$-value of 0.9 .

The 5-year OS for all patients was $44 \% \pm 10 \%$ (Table 3 ). The only significant factor was the stage: 5-year OS was $54 \% \pm 13 \%$ and $16 \% \pm 8 \%$ in T3 and T4, respectively $(P=0.02)$. The OS did not differ significantly according to histopathology types $(P=0.7)$. The PORT group of patients showed a 5 -year OS of $52 \% \pm 11 \%$, in contrast to the non-PORT group of patients (38\% $\pm 8 \%$ ); however, the $P$-value was nonsignificant $(P=0.3)$, as shown in Figure 2 .

Using multivariate analysis, we found PORT, stage, and extravesical extension (positive surgical margins) to be important prognostic factors for LRR. Stage and lymph node status were important prognosticators for DMR.

\section{Toxicity profile}

The most common acute grade 3 complication was gastrointestinal toxicity, with diarrhea in 19\% (17/92 patients), and proctitis required treatment only in 12 patients $(13 \%)$.

Chronic adverse effects observed were of a rare and a mild nature. Seven (8\%) patients in the PORT group developed intestinal obstruction within 2 years of completion of treatment. All the patients required surgical intervention.

\section{Discussion}

Theoretically, PORT is justifiable after RC in locally advanced bladder cancer. However, the role of PORT in bladder cancer is still controversial in many Western publications compared with in Egyptian ones. ${ }^{1-8}$ In our cohort, patients treated with PORT had the worst clinicopathological features. The most common argument against the use of PORT is the radiation-induced complications, especially the late small bowel complications, as seen in our study ( $8 \%$ of cases had small bowel obstruction). However, this small bowel obstruction rate is significantly lower than that reported by Reisinger et al $(\sim 37 \%) .{ }^{10}$ Higher rates of small bowel complications are related to the large volume of irradiated small bowel and dose. ${ }^{10}$

In contrast, Zaghloul et al reported much lower small bowel complication rates $(4.5 \%)$. The reason could be explained by the lower total dose $(45 \mathrm{~Gy} / 25)$ and the lower dose per fraction (1.8 Gy), and in one group, hyperfractionation was used. ${ }^{7}$ However, Zaghloul et al also reported a small bowel obstruction of $6 \%$ (similar to our findings) in another series of adenocarcinoma bladder patients treated with cystectomy and PORT (4/69 patients). ${ }^{11}$

In our study, LRR was comparable to Greven et al $(51 \%),{ }^{12}$ Volkmer et al $(48.6 \%),{ }^{13}$ and Cheng et al $(51 \%) .{ }^{14}$ In contrast, LRR in our cohort was higher compared with

Table 3 Five-year disease-free survival and 5-year overall survival

\begin{tabular}{|c|c|c|c|c|c|}
\hline Prognostic factor & $\begin{array}{l}\text { Number } \\
\text { of patients }\end{array}$ & $\begin{array}{l}\text { Five-year disease-free } \\
\text { survival }(53 \% \pm I I \%)\end{array}$ & $P$-value & $\begin{array}{l}\text { Five-year overall } \\
\text { survival }(44 \% \pm 10 \%)\end{array}$ & $P$-value \\
\hline Radiotherapy & & & 0.04 & & 0.3 \\
\hline Postoperative radiotherapy & 92 & $65 \% \pm 13 \%$ & & $52 \% \pm 11 \%$ & \\
\hline No postoperative radiotherapy & 78 & $40 \% \pm 9 \%$ & & $38 \% \pm 8 \%$ & \\
\hline Stage & & & 0.02 & & 0.02 \\
\hline T3 & 102 & $60 \% \pm 15 \%$ & & $54 \% \pm 13 \%$ & \\
\hline $\mathrm{T} 4$ & 68 & $20 \% \pm 6 \%$ & & $16 \% \pm 8 \%$ & \\
\hline Pathological type & & & 0.9 & & 0.7 \\
\hline Transitional & 104 & $59 \% \pm 7 \%$ & & $50 \% \pm 6 \%$ & \\
\hline Squamous & 53 & $47 \% \pm 14 \%$ & & $40 \% \pm 12 \%$ & \\
\hline
\end{tabular}




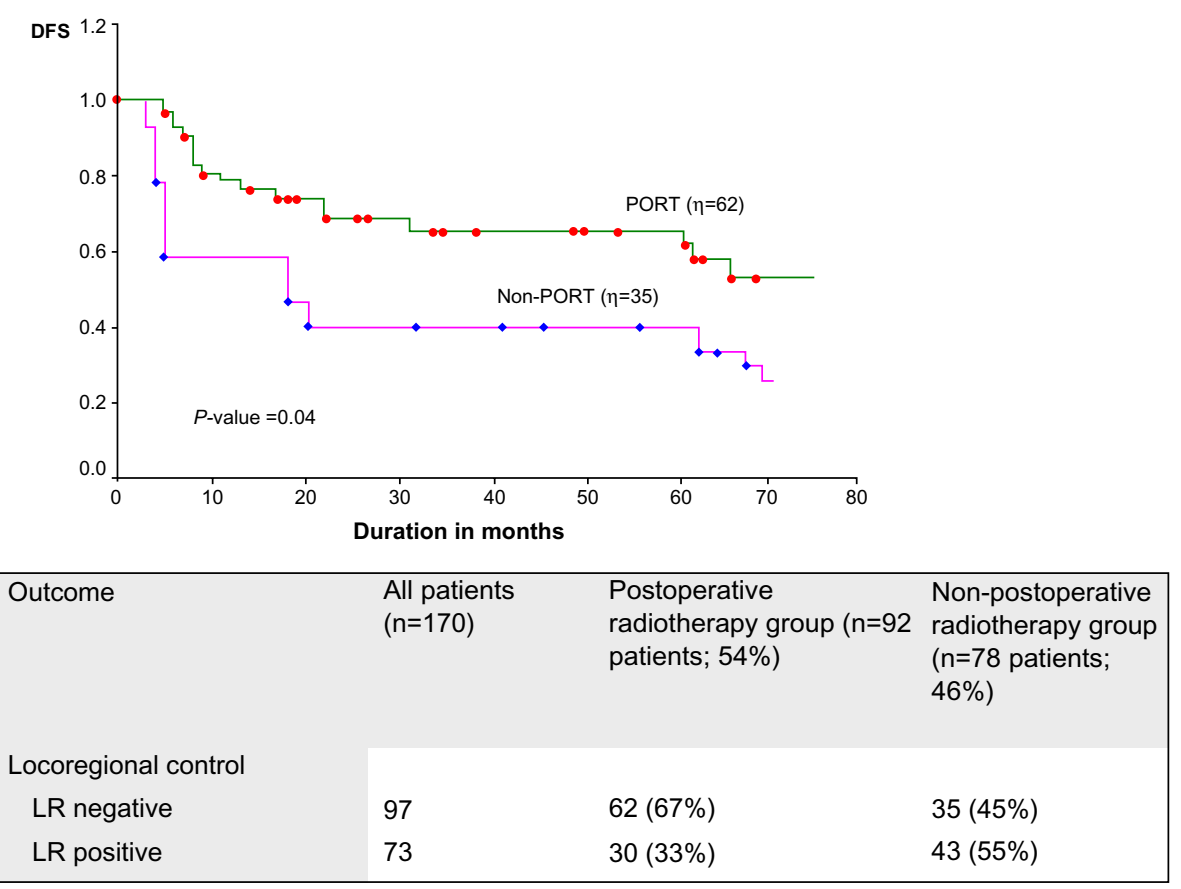

Figure I Disease-free survival in postoperative radiotherapy (PORT) and non-postoperative radiotherapy (non-PORT) group of patients. Abbreviations: DFS, disease-free survival; LR, locoregional recurrence.

Gupta et al $(29 \%)^{15}$ and Hassan et al $(30 \%) .{ }^{16}$ The reason for higher LR in our study compared with these studies can be explained by the predominant $\mathrm{T} 3$ and $\mathrm{T} 4$ cohort.

The DMR in our study are consistent with that of related studies..$^{17,18}$
It is interesting to mention that, in our study, PORT improved the 5 -year DFS $(65 \% \pm 13 \%$ versus $40 \% \pm 9 \%)$ with a $P$-value of 0.04 . These results are better than those reported by Cozzarini et al $(44 \%)^{19}$ and Zaghloul et al $(47 \%)^{7}$ and were similar to three other Egyptian studies. ${ }^{11,17,20}$

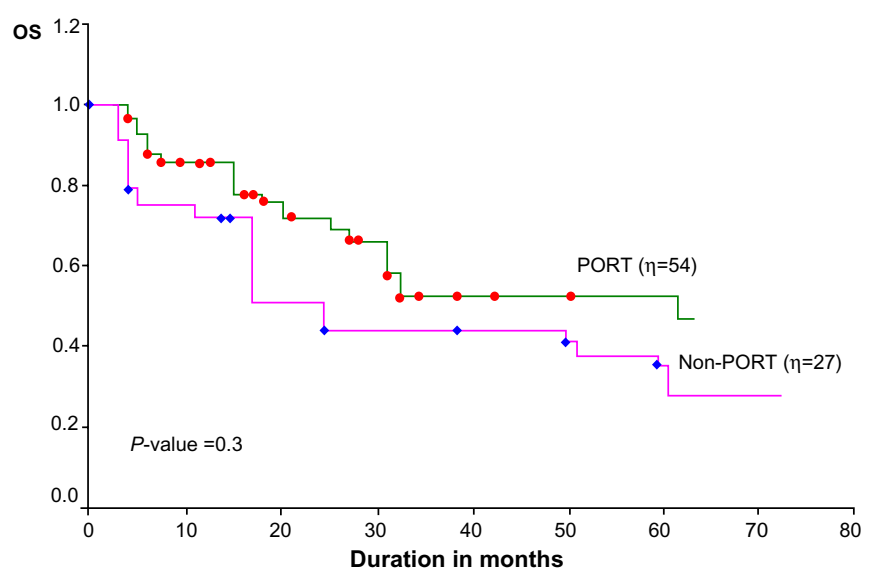

\begin{tabular}{|lccc|}
\hline & $\begin{array}{c}\text { Postoperative } \\
\text { radiotherapy group } \\
(n=92 \text { patients; } 54 \%)\end{array}$ & $\begin{array}{c}\text { Non-postoperative } \\
\text { radiotherapy group } \\
(n=78 \text { patients; } 46 \%)\end{array}$ \\
$\begin{array}{l}\text { Outcome } \\
\text { survival status } \\
\text { Alive }\end{array}$ & All patients $(n=170)$ & $54(58 \%)$ & $27(35 \%)$ \\
Dead & 81 & $38(42 \%)$ & $51(65 \%)$ \\
\hline
\end{tabular}

Figure 2 Overall survival for postoperative radiotherapy (PORT) and non-postoperative radiotherapy (non-PORT) groups of patients. Abbreviation: OS, overall survival. 
Pathological stage was considered the most important prognostic factor in bladder cancer patients after RC. We evaluated the effect of stage III and IV cancer on DFS and found that there is significant difference between stage III $(60 \% \pm 15 \%)$ and stage IV $(20 \% \pm 6 \%)$ patients, with $P=0.02$. These data were comparable to the Greven series, with DFS $51 \%$ in patients with stage pT3. ${ }^{12}$ Our results were found to be better than those reported by Visser et al, with 5-year DFSs of $31 \%$ and $23 \%$ for cancer stages III and IV, respectively. ${ }^{21}$ The 5-year OS in our series was $44 \% \pm 10 \%$.

Nishiyama et al showed an OS of $59 \%$ in pT3 and $43 \%$ in $\mathrm{pT} 4 ;^{5}$ in addition, Takahashi et al showed an OS of $47 \%$ and $38 \%$ in pT3 and pT4, respectively. ${ }^{6}$ These findings are comparable to our results. The PORT had no significant effect on the OS with $P=0.3$ in our study, which is consistent with other studies. ${ }^{11,13,15}$

The histopathological types (transitional carcinoma versus squamous carcinoma) did not affect the DFS or OS in our study, with $P=0.9$ and $P=0.7$, respectively. Rogers et $\mathrm{al}^{22}$ reported a 5 -year OS of $60 \% \pm 2 \%$ after RC for transitional and $55 \% \pm 11 \%$ for squamous cell carcinoma. A recent large series review of more than 28,000 patients in the Netherlands ${ }^{23}$ has concluded that the survival of muscle-invasive bladder cancer is not affected by histopathology subtypes (transitional cell, squamous cell, and adenocarcinoma).

Limitations of our study were its retrospective nature, that a possible selection bias could not be excluded and that adenocarcinoma cases were not analyzed (which is why there were no data regarding its outcome and the decreased number of orthotopic diversions; a possible reason was that the majority of patients had locally advanced disease in our cohort).

\section{Conclusion}

Standard treatment for locally advanced bladder cancers is $\mathrm{RC}$ with or without neoadjuvant chemotherapy; however, patients treated with up-front RC can benefit from PORT by decreasing LR rates. Large studies are warranted with concurrent chemotherapy to determine the real benefit of PORT.

\section{Disclosure}

The authors report no conflicts of interest in this work.

\section{References}

1. Stein JP, Lieskovsky G, Cote R, et al. Radical cystectomy in the treatment of invasive bladder cancer: long-term results in 1,054 patients. J Clin Oncol. 2001;19(3):666-675.
2. Ghoneim MA, el-Mekresh MM, el-Baz MA, el-Attar IA, Ashamallah A. Radical cystectomy for carcinoma of the bladder: critical evaluation of the results in 1,026 cases. J Urol. 1997;158(2):393-399.

3. Ghoneim MA, Abdel-Latif M, el-Mekresh M, et al. Radical cystectomy for carcinoma of the bladder: 2,720 consecutive cases 5 years later. J Urol. 2008;180(1):121-127.

4. Madersbacher S, Hochreiter W, Burkhard F, et al. Radical cystectomy for bladder cancer today - a homogeneous series without neoadjuvant therapy. J Clin Oncol. 2003;21(4):690-696.

5. Nishiyama H, Habuchi T, Watanabe J, et al. Clinical outcome of a largescale multi-institutional retrospective study for locally advanced bladder cancer: a survey including 1131 patients treated during 1990-2000 in Japan. Eur Urol. 2004;45(2):176-181.

6. Takahashi A, Tsukamoto T, Tobisu K, et al. Radical cystectomy for invasive bladder cancer: results of multi-institutional pooled analysis. Jpn J Clin Oncol. 2004;34(1):14-19.

7. Zaghloul MS, Awwad HK, Akoush HH, Omar S, Soliman O, el Attar I. Postoperative radiotherapy of carcinoma in bilharzial bladder: improved disease free survival through improving local control. Int J Radiat Oncol Biol Phys. 1992;23(3):511-517.

8. Zaghloul MS, Awwad HK, Soliman O, et al. Postoperative radiotherapy of carcinoma in bilharzial bladder using a three-fractions per day regimen. Radiother Oncol. 1986;6(4):257-265.

9. Edge SB, Byrd DR, Compton CC, et al, editors. AJCC Cancer Staging Manual. Bladder Cancer. 7th ed. New York, NY: Springer; 2010: 497-505.

10. Reisinger SA, Mohiuddin M, Mulholland SG. Combined pre- and postoperative adjuvant radiation therapy for bladder cancer - a ten year experience. Int J Radiat Oncol Biol Phys. 1992;24(3):463-468.

11. Zaghloul MS, Nouh A, Nazmy M, et al. Long-term results of primary adenocarcinoma of the urinary bladder: a report on 192 patients. Urol Oncol. 2006;24(1):13-20.

12. Greven KM, Spera JA, Solin LJ, Morgan T, Hanks GE. Local recurrence after cystectomy alone for bladder carcinoma. Cancer. 1992;69(11): 2767-2770.

13. Volkmer BG, Kuefer R, Bartsch GC Jr, Gust K, Hautmann RE. Oncological followup after radical cystectomy for bladder cancer-is there any benefit? J Urol. 2009;181(4):1587-1593.

14. Cheng L, Weaver AL, Leibovich BC, et al. Predicting the survival of bladder carcinoma patients treated with radical cystectomy. Cancer. 2000;88(10):2326-2332.

15. Gupta NP, Kolla SB, Seth A, et al. Radical cystectomy for bladder cancer: A single center experience. Indian J Urol. 2008;24(1):54-59.

16. Hassan JM, Cookson MS, Smith JA Jr, Chang SS. Patterns of initial transitional cell recurrence in patients after cystectomy. J Urol. 2006; 175(6):2054-2057.

17. Zaghloul MS, El Baradie M, Nouh MA, Abdel-Fatah S, Taher A, Shalaan M. Prognostic index for primary adenocarcinoma of the urinary bladder. Gulf J Oncolog. 2007;1(2):47-54.

18. Vale CL; Advanced Bladder Cancer (ABC) Meta-analysis Collaboration. Neoadjuvant chemotherapy in invasive bladder cancer: update of a systematic review and meta-analysis of individual patient data advanced bladder cancer (ABC) meta-analysis collaboration. Eur Urol. 2005;48(2):202-205.

19. Cozzarini C, Pelegrini D, Fallini M, et al. Reappraisal of the role of adjuvant radiotherapy in muscle-invasive transitional cell carcinoma of the bladder. Int J Radiat Oncol Biol Phys. 1999;45(3):221-222.

20. Zaghloul MS, Mohran TZ, Saber RA, Agha N. Postoperative radiotherapy in bladder cancer. J Egypt Natl Canc Inst. 2002;14:161-168.

21. Visser O, Nieuwenhuijzen JA, Horenblas S; Members of the Urological Oncology Working Group of the Comprehensive Cancer Centre Amsterdam. Local recurrence after cystectomy and survival of patients with bladder cancer: a population based study in greater amsterdam. J Urol. 2005;174(1):97-102. 
22. Rogers CG, Palapattu GS, Shariat SF, et al. Clinical outcomes following radical cystectomy for primary nontransitional cell carcinoma of the bladder compared to transitional cell carcinoma of the bladder. J Urol. 2006;175(6):2048-2053.
23. Ploeg M, Aben KK, Hulsbergen-van de Kaa CA, Schoenberg MP, Witjes JA, Kiemeney LA. Clinical epidemiology of nonurothelial bladder cancer: analysis of The Netherlands Cancer Registry. J Urol. 2010;183(3):915-920.

\section{Publish your work in this journal}

Cancer Management and Research is an international, peer-reviewed open access journal focusing on cancer research and the optimal use of preventative and integrated treatment interventions to achieve improved outcomes, enhanced survival and quality of life for the cancer patient The journal welcomes original research, clinical \& epidemiological studies, reviews \& evaluations, guidelines, expert opinion \& commentary, case reports \& extended reports. The manuscript management system is completely online and includes a very quick and fair peerreview system, which is all easy to use. Visit http://www.dovepress.com/ testimonials.php to read real quotes from published authors.

Submit your manuscript here: http://www.dovepress.com/cancer-management-and-research-journal 